\title{
Properdin and C3 Proactivator: Alternate Pathway Components in Human Glomerulonephritis
}

\author{
Robert H. McLean and Alfred F. Michael \\ From the Department of Pediatrics, University of Minnesota Hospitals, \\ Minneapolis, Minnesota 55455
}

A в S T R A C T Serological and immunopathological studies of human glomerulonephritis have suggested that alternate pathways of activation of the third component of complement may be important in some forms of glomerulonephritis. We have investigated the role of two alternate pathway proteins, properdin and C3 proactivator, in 22 patients with chronic membranoproliferative glomerulonephritis, 21 patients with systemic lupus erythematosus, 20 patients with acute poststreptococcal glomerulonephritis, and 19 patients with other forms of renal disease. $\mathrm{C} 3$ (measured at $\beta_{1} \mathrm{~A}$ ), properdin, and $\mathrm{C} 3$ proactivator were assayed by single radial immunodiffusion.

In sera with low $\beta_{1} \mathrm{~A}(<2 \mathrm{SD})$, mean properdin was most significantly decreased in patients with acute poststreptococcal glomerulonephritis but was also significantly decreased in chronic membranoproliferative glomerulonephritis and in untreated systemic lupus erythematosus. Properdin levels in other renal disease, acute glomerulonephritis, and chronic membranoproliferative glomerulonephritis with normal $\beta_{1} A$ levels were not significantly different from normal. A positive correlation between $\beta_{1} \mathrm{~A}$ and properdin levels in individual sera was present in all diseases except systemic lupus erythematosus.

Serum C3 proactivator was markedly decreased in active systemic lupus erythematosus and there was a positive correlation between $\beta_{1} \mathrm{~A}$ and $\mathrm{C} 3$ proactivator levels in systemic lupus erythematosus and other renal diseases but not acute poststreptococcal glomerulonephritis.

Properdin in fresh sera from four patients with systemic lupus erythematosus and five with chronic membranoproliferative glomerulonephritis showed increased migration toward the cathode on immunoelectrophoresis, suggesting in vivo change of the properdin molecule.

A preliminary report of these findings was presented at the Society for Pediatric Research, 25 May 1972, Washington, D. C.

Received for publication 7 August 1972 and in revised form 10 November 1972.
The observation of reduced serum levels of properdin and C3 proactivator and altered electrophoretic migration of properdin in some patients with glomerulonephritis provide new evidence for participation of these alternate pathway proteins in glomerulonephritis.

\section{INTRODUCTION}

There is considerable evidence that immunological factors are important in the pathogenesis of some forms of human glomerulonephritis (1). The effector mechanism of this injury involves in part the complement system. The existence of an alternate pathway of activation of complement which enters the complement sequence at C3 has been demonstrated in vitro by several workers (2-4), but the relevance of this pathway in human glomerulonephritis is unknown.

The properdin system as originally described (2) consists of the normal serum protein properdin, magnesium, and two other serum factors: Factor A (hydrazine sensitive) (5) and Factor B (heat labile) (6). At $37^{\circ} \mathrm{C}$ in the presence of polysaccharides such as zymosan or inulin, the properdin system activates $\mathrm{C} 3$. A definite role of the properdin system in human disease has been suggested by the demonstration of reduced serum levels in certain renal diseases $(7,8)$ and its presence in glomerular deposits in acute poststreptococcal glomerulonephritis (AGN) ${ }^{1}$ and chronic membranoproliferative glomerulonephritis (CMPGN) associated with hypocomplementemia (9).

Sandberg, Osler, Shin, and Oliveira (3) demonstrated that the Fc fragment of guinea pig $\gamma 2$ activated

${ }^{1}$ Abbreviations used in this paper: AGN, acute poststreptococcal glomerulonephritis; C3PA, C3 proactivator; CMPGN, chronic membranoproliferative glomerulonephritis; $\mathrm{CoF}$, anticomplementary factor from cobra venom; $\mathrm{GAH} \beta_{1} \mathrm{C}$, goat antihuman $\beta_{1} C$; GAHC3PA, goat antihuman C3PA; HSF, hydrazine-sensitive factor; PBS, phosphate-buffered saline; Pc, properdin with increased cathodal migration on electrophoresis; RAHP, rabbit antihuman properdin; SLE, systemic lupus erythematosus. 
the entire complement sequence, whereas the $F\left(a b^{\prime}\right)_{2}$ fragment of both $\gamma 1$ and $\gamma 2$ activated only the terminal complement sequence (C3-9). Both $\gamma 2$ and $\gamma 1$ aggregates and $F\left(a b^{\prime}\right)$, fragments have been shown to activate the C3 activator system $(10,11)$.

The $\mathrm{C} 3$ activator system $(4,12)$ includes a normal serum protein $\mathrm{C} 3$ proactivator (C3PA) which activates $\mathrm{C} 3$ in the presence of cations and an activating substance such as cobra venom, polysaccharides, or certain immunoglobulins. Other proteins of the C3PA pathway include a hydrazine-sensitive factor (HSF) which appears to be C3. An activated fragment of C3, C3b ( $\mathrm{HSFa}$ ), and a $3 \mathrm{~S}-\alpha$ globulin (C3PA convertase) are necessary for activation of C3PA. C3PA has the same antigenic determinants as glycine-rich $\beta$-glycoprotein which has recently been reported to have Factor $B$ activity in the properdin system (13). The relationship of the properdin system to the C3 activator system is presently unclear.

The purpose of this study was to investigate the possible role of the alternate pathway in glomerulonephritis in man, as reflected by changes in serum levels of properdin, C3PA, and $\beta_{1} A$.

\section{METHODS}

\section{Patients}

The patients were seen at the University of Minnesota Hospitals and were divided into four groups.

(a) Chronic membranoproliferative glomerulonephritis (CMPGN) (9 males, 13 females). As previously reported, the diagnosis of CMPGN was based on the clinical picture, the renal pathological findings by light and immunofluorescent microscopy, and the presence of hypocomplementemia at some time during the period of observation (9). Patients ranged in age from 8 to $35 \mathrm{yr}$.

(b) Systemic lupus erythematosis (SLE) (5 males, 16 females) was diagnosed by the presence of anti-DNA antibody and LE cells, hypocomplementemia, and systemic symptoms. Fever, arthritis, skin lesions, and abnormal urinary sediment were usually present at some time during the patient's course. Patients ranged in age from 11 to $42 \mathrm{yr}$.

(c) Acute poststreptococcal glomerulonephritis (AGN) (11 males, 9 females). This included 2 patients with sporadic AGN and 18 patients with epidemic AGN. The clinical and morphologic features of the latter group of patients have been reported previously (14). Patients ranged in age from $1 \frac{1}{2}$ to $13 \mathrm{yr}$.

(d) Other renal diseases (12 males, 7 females). This group included five patients with vasculitis, two with anaphylactoid purpura, two with focal glomerulonephritis, four with proliferative glomerulonephritis (not poststreptococcal); two with membranous glomerulopathy, one with acute tubular necrosis, one with hereditary angioneurotic edema and glomerulonephritis, one with hemolytic-uremic syndrome, and one with end-stage renal disease of unknown etiology. Patients ranged in age from 3 to $21 \mathrm{yr}$.

\section{Collection of sera}

Blood specimens were drawn into serum tubes and allowed to clot at room temperature. Sera were centrifuged, separated, and one aliquot frozen at $-70^{\circ} \mathrm{C}$ within $6 \mathrm{~h}$. A second aliquot $(0.3 \mathrm{ml})$ with sodium azide $(0.02 \%)$ was tightly sealed and placed in a $37^{\circ} \mathrm{C}$ incubator for 7 days for conversion of all $\beta_{1} C$ to $\beta_{1} A$ (aged sera). The aliquot kept at $-70^{\circ} \mathrm{C}$ was used for measurement of C3PA and properdin by immunodiffusion methods. Sera from the 18 patients with epidemic AGN had been stored at $-70^{\circ} \mathrm{C}$ since 1965.

Immunodiffusion assay of $\beta_{1} \mathrm{C} / \beta_{1} \mathrm{~A}$, properdin, and C3PA

Immunodiffusion assays were carried out according to a modification of the method of Mancini, Carbonara, and Heremans (15). Glycine-saline-EDTA (0.002 M) buffer was used for all dilutions (glycine $7.5 \mathrm{~g}$, sodium chloride $8.5 \mathrm{~g}$, dissodium EDTA $0.7445 \mathrm{~g}, 1 \mathrm{~N}$ sodium hydroxide $2.5 \mathrm{ml}, \mathrm{pH}$ to 8.2 with $\left.10 \% \quad \mathrm{Na}_{2} \mathrm{CO}_{3}\right)$. An appropriate dilution of antiserum in $1 \%$ agarose was poured into disposable square Petri plates which were on a flat surface and then stored in the cold for not more than 30 days. 36 2-mm diameter wells were made on each plate. Serial dilutions of the reference serum for the protein being measured were placed on every plate for construction of the standard curve of area vs. concentration. Specimens were assayed in duplicate using $5 \mu \mathrm{l}$ in each well, delivered by a microsyringe (Hamilton Co., Whittier, Calif.). After full development of precipitin rings in a humid environment at room temperature, the diameters were measured using a measuring magnifier (Bausch \& Lomb, Inc., Rochester, N. Y.) and the area calculated. The concentration of the protein was then determined from the standard curve of area vs. concentration.

\section{$\beta_{1} \mathrm{C} / \beta_{1} \mathrm{~A}$}

Human $\beta_{1} \mathrm{C}$ was isolated by column chromatography according to the method of Müller-Eberhard, Nilsson, and Aronsson (16). Goat antiserum $\left(\mathrm{GAH} \beta_{1} \mathrm{C}\right)$ produced by multiple injections incorporated in Freund's adjuvant was used in the immunodiffusion assay of $\beta_{1} A$. This antiserum produced a single line by double diffusion in agarose gel against normal human serum. In fresh serum a single arc in the $\beta$-region was found by immunoelectrophoresis in Ionagar (Colab Labs., Inc., Glenwood, Ill.). Double diffusion revealed no lines of identity between human serum and $\mathrm{GAH} \beta_{1} \mathrm{C}$, goat antihuman C3PA (GAHC3PA), and rabbit antihuman properdin (RAHP).

The aged reference serum used in $\beta_{1} A$ assays was kindly quantitated by Dr. Clark West and stored at $-20^{\circ} \mathrm{C}$. Native $C 3$ has three antigenic sites, $C 3 a, C 3 c\left(\beta_{1} A\right)$, and C3d. With aging, the C3a site is lost and C3c $\left(\beta_{1} A\right)$ is the dominant antigenic site. Serum levels of complement reported in this paper are a measure of this antigenic site. For immunodiffusion assay, aliquots of the patients' aged sera were diluted $1 / 10$ in normal saline, applied to the immunodiffusion plate, and allowed to develop for $21 \mathrm{~h}$ before being read. The average $\beta_{1} A$ concentration of 33 orthopedic patients (aged 1-18 yr) without systemic or renal diseases was $165 \pm 41 \mathrm{mg} / 100 \mathrm{ml}$ ( $1 \mathrm{SD}$ ) with a range of $100-247$ $\mathrm{mg} / 100 \mathrm{ml}$. The concentration in a single serum determined on 10 different occasions averaged $151 \pm 7 \mathrm{mg} / 100 \mathrm{ml}$ (1 $\mathrm{SD}),(\mathrm{SE} \pm 2.2)$.

\section{Properdin}

Human serum properdin was isolated according to published methods (17). Antiserum was produced in rabbits by multiple injections of properdin incorporated in com- 
plete Freund's adjuvant. The specificity of this antiserum has previously been reported. Double diffusion of RAHP against normal human serum yielded a single line and gave no line of identity with GAHC3PA. As previously reported, the RAHP did not react with $\mathrm{Clq}$, $\mathrm{C} 3$, or $\mathrm{C} 5$; in addition, there was no reaction with isolated C3PA or with C3PA in fresh and aged serum. As previously described, immunoelectrophoresis of fresh normal human serum for properdin produced a single precipitin line migrating in the $\beta$-globulin region (18).

Serial dilutions in phosphate-buffered saline (PBS) $(0.15$ $\mathrm{M}$ sodium chloride and $0.01 \mathrm{M}$ sodium phosphate, $\mathrm{pH} 7.40$ ) of isolated properdin showed a linear relationship by immunodiffusion between dilutions of $1 / 2$ to $1 / 8$. The reference serum for properdin assay had a concentration of 4.64 $\mu \mathrm{g} \mathrm{N}$ per $\mathrm{ml}$ of properdin and showed a linear relationship between area and concentration in dilutions of $1 / 1$ to $1 / 16$. For immunodiffusion assay ${ }^{2}$ a $1 / 2$ dilution of the patients' sera which had been stored at $-70^{\circ} \mathrm{C}$ was placed in the wells. The reaction was allowed to proceed for at least $72 \mathrm{~h}$. Precipitin rings were visible at the end of $72 \mathrm{~h}$, but were too faint to be accurately read. The plates were washed in saline with two changes of saline over $48 \mathrm{~h}$, and then soaked in $0.1 \%$ tannic acid for $10 \mathrm{~min}$. This rinse was followed by a $10 \mathrm{~min}$ wash with $0.2 \%$ 8-anilino-1-naphthalenesulfonic acid (ANSA) in 5\% acetic acid and $1 \mathrm{~min}$ in $5 \%$ acetic acid alone (Analytical Chemists, Inc., Palo Alto, Calif.). The plate could then be washed with saline and diameters read. Aliquots of the normal reference serum

${ }^{2}$ Westberg, N. G., R. H. McLean, and A. F. Michael. Determination of serum properdin levels by immunodiffusion. Int. Arch. Allergy Appl. Immunol. In press. were stored at $-70^{\circ} \mathrm{C}$ and were arbitrarily given a level of $100 \%$. All results were expressed as percent of this reference serum.

The normal mean serum properdin level for 33 children (age 1-18 yr) was $107 \pm 17 \%$ (1 SD) with a range of $50-173 \%$. The concentration of properdin in a single serum measured on 11 separate occasions had a mean of 127 $\pm 7 \%$, (1 SD), (SE 2).

\section{C3 proactivator (C3PA)}

Human C3PA was isolated according to the method of Götze and Müller-Eberhard (4). Trace amounts of IgG in the final preparation of C3PA were removed by passage over a Sepharose 4B immunoadsorbent column (Pharmacia Fine Chemicals Inc., Piscataway, N. J.) coupled to antiIgG. Pure C3PA showed no reactivity with antiserum to IgG, IgM, IgA, $\beta_{1} C$, or properdin. Antiserum was prepared in a goat by multiple subcutaneous injections in complete Freund's adjuvant. Double diffusion of fresh serum against GAHC3PA in agarose showed complete identity with GAHC3PA antiserum kindly provided by Dr. Müller-Eberhard and with rabbit antiserum to $\mathrm{C} 3$ activator (glycine-rich $\beta$-glycoprotein II) obtained from Behringwerke AG, Marburg-Lahn, West Germany. There was no identity when serum was reacted against GAHC3PA and GAH $\beta_{1} C$ that had been prepared against $\beta_{1} \mathrm{~A}$ absorbed to zymosan.

By immunodiffusion assay a straight line was described when a $1 / 2$ to $1 / 16$ dilution of isolated C3PA was plotted against area. The amount of C3PA in a normal reference serum was assayed using isolated C3PA containing $73.5 \mu \mathrm{g}$ $\mathrm{N}$ per $\mathrm{ml}$ for the standard curve. Protein nitrogen was measured according to the method of Lowry using bovine

TABLE I

Mean Serum Levels of $\beta_{1} A$, Properdin, and C3PA Determined by Immunodiffusion Assay in Patients with CMPGN, SLE, AGN, and Other Renal Diseases. Values Grouped according to

Level of Serum $\beta_{1} A^{*}$

\begin{tabular}{|c|c|c|c|c|c|c|}
\hline \multirow[b]{2}{*}{ Disease } & \multicolumn{3}{|c|}{ Low $\beta_{1}$ A levels* } & \multicolumn{3}{|c|}{ Normal $\beta_{1}$ A levels* } \\
\hline & $\beta_{1} \mathrm{~A} \ddagger$ & $\begin{array}{l}\text { Proper- } \\
\text { din }\end{array}$ & $\mathrm{C} 3 \mathrm{PA}$ & $\beta_{1} \mathrm{~A} \ddagger$ & $\begin{array}{l}\text { Proper- } \\
\text { din }\end{array}$ & C3PA \\
\hline & $\begin{array}{c}\mathrm{mg} / \\
100 \mathrm{ml}\end{array}$ & $\begin{array}{c}\% \\
\text { normal }\end{array}$ & $\mu g N / m l$ & $\begin{array}{l}m g / \\
100 \mathrm{ml}\end{array}$ & $\begin{array}{c}\% \\
\text { normal }\end{array}$ & $\mu \mathrm{g} \mathrm{N} / \mathrm{ml}$ \\
\hline CMPGN & $\begin{array}{c}42 \pm 24 \\
(18) \S\end{array}$ & $\begin{array}{c}72 \pm 15 \\
(18)\end{array}$ & $\begin{array}{r}33 \pm 7 \\
(14)\end{array}$ & $\begin{array}{c}115 \pm 33 \\
(11)\end{array}$ & $\begin{array}{c}92 \pm 31 \\
(11)\end{array}$ & $\begin{array}{c}31 \pm 11 \\
(7)\end{array}$ \\
\hline SLE & $\begin{array}{c}65 \pm 18 \\
(16)\end{array}$ & $\begin{array}{c}90 \pm 25 \\
(16)\end{array}$ & $\begin{array}{r}27 \pm 9 \\
(13)\end{array}$ & $\begin{array}{c}106 \pm 17 \\
(10)\end{array}$ & $\begin{array}{c}95 \pm 27 \\
(10)\end{array}$ & $\begin{array}{r}33 \pm 9 \\
(8)\end{array}$ \\
\hline AGN & $\begin{array}{c}44 \pm 24 \\
(14)\end{array}$ & $\begin{array}{c}60 \pm 24 \\
(14)\end{array}$ & $\begin{array}{c}36 \pm 10 \\
(12)\end{array}$ & $\begin{array}{c}113 \pm 10 \\
(10)\end{array}$ & $\begin{array}{c}95 \pm 24 \\
(10)\end{array}$ & $\begin{array}{c}46 \pm 15 \\
(8)\end{array}$ \\
\hline Other renal diseases & & & & $\begin{array}{c}151 \pm 45 \\
(19)\end{array}$ & $\begin{array}{c}124 \pm 43 \\
(19)\end{array}$ & $\begin{array}{c}40 \pm 11 \\
(15)\end{array}$ \\
\hline Normal & & & & $\begin{array}{c}165 \pm 41 \\
(33)\end{array}$ & $\begin{array}{c}107 \pm 17 \\
(33)\end{array}$ & $\begin{array}{c}46 \pm 12 \\
(32)\end{array}$ \\
\hline
\end{tabular}

* Low $\beta_{1} \mathrm{~A}$ levels indicate values less than $83 \mathrm{mg}$ per $100 \mathrm{ml}$ (2 SD below mean of normal); normal $\beta_{1} \mathrm{~A}$ levels indicate values that are equal to or greater than $83 \mathrm{mg}$ per $100 \mathrm{ml}$. Multiple sera from patients were first grouped by $\beta_{1} \mathrm{~A}$ level and then averaged.

$\ddagger \beta_{1} \mathrm{~A}$ level in each patient is calculated by averaging the values of all sera from that patient for which properdin levels are also available. The values represent the mean \pm 1 SD.

$\$$ The number in parenthesis is the number of patients with the indicated disease within each group. In seven patients with CMPGN, five patients with SLE, and four patients with AGN, values are included in both $\beta_{1} \mathrm{~A}$ subgroups since sera were obtained at varying stages of the disease. 
serum albumin (Armour Pharmaceutical Co., Chicago, I11.) as a standard. Recovery of isolated C3PA added to a 1/8 dilution of the reference pool was $106 \%$. For immunodiffusion assay serial twofold dilutions in PBS of a normal reference serum were placed on each assay plate. A reference serum containing $33.3 \mu \mathrm{g} \mathrm{N}$ per $\mathrm{ml}$ was used as a standard in all subsequent immunodiffusion assays for C3PA.

Patients' sera were diluted $1 / 4$ or $1 / 3$ in PBS before immunodiffusion. The concentration of C3PA in the sera of 32 normal children aged $1-18$ was $46 \pm 12 \mu \mathrm{g} \mathrm{N}$ per ml (1 SD). The range was $28-76 \mu \mathrm{g} \mathrm{N}$ per $\mathrm{ml}$ and seven assays of the same serum at different times revealed a concentration of $35 \pm 4 \mu \mathrm{g} \mathrm{N}$ per $\mathrm{ml}$ (1 SD), ( $\mathrm{SE} \pm 1.3)$.

\section{Immunoelectrophoresis of properdin}

Properdin immunoelectrophoresis (18) was performed in $2 \%$ Noble agar using the glycine-saline-EDTA (0.002 M) buffer previously described (immunodiffusion assay of $\beta_{1} \mathrm{C} / \beta_{1} \mathrm{~A}$ properdin and $\mathrm{C} 3 \mathrm{PA}$ ). Only sera kept at $-70^{\circ} \mathrm{C}$ were examined. A voltage of $4-5 \mathrm{~V} / \mathrm{cm}$ was measured across the bath supplied by a constant current $(50 \mathrm{~mA})$ power supply. Immunoelectrophoresis was performed on human sera placed in 4-mm wells for $4 \mathrm{~h}$ at room temperature. RAHP (diluted 1/12) was placed in the troughs and precipitin arcs appeared by $12-18 \mathrm{~h}$ with full development after 3 days. Arcs were made more visible by using goat antiserum against rabbit IgG (19).

\section{In vitro studies}

Cobra venom factor effect on properdin. The anticomplementary factor from cobra venom Naja naja ( $\mathrm{CoF}$ ) was isolated by the method of Müller-Eberhard and Fjellstrom (20). $1 \mathrm{U}$ of $\mathrm{CoF}$ was equal to $3.75 \mu \mathrm{g}$ protein as assayed by the method of Müller-Eberhard and Fjellstrom in which $1 \mathrm{U}$ of $\mathrm{CoF}$ causes $50 \%$ decrease in the hemolytic complement in $0.5 \mathrm{ml}$ of a $1: 20$ dilution of fresh serum.

1,2 , and $20 \mathrm{U}$ of $\mathrm{CoF}$ were incubated with $1.0 \mathrm{ml}$ of fresh human serum at $37^{\circ} \mathrm{C}$ for $30 \mathrm{~min}$. The reaction was stopped by freezing at $-70^{\circ} \mathrm{C}$. Immunoelectrophoresis for properdin, $\beta_{1} \mathrm{C}$, and $\mathrm{C} 3 \mathrm{PA}$ was performed on the serum as previously described $(4,18)$.

Endotoxin effect on properdin. Endotoxin (Escherichia coli 026:B6 lipopolysaccharide B [Difco Labs., Detroit, Mich.]) was suspended in PBS in a concentration of 600 $\mu \mathrm{g}$ per $\mathrm{ml} ; 3 \mu \mathrm{l}, 10 \mu \mathrm{l}$, and $75 \mu \mathrm{l}$ were added to $0.5 \mathrm{ml}$ of fresh human serum $(3.6,12,90 \mu \mathrm{g}$ per $\mathrm{ml}$ serum, respectively). After $30 \mathrm{~min}$ incubation at $37^{\circ} \mathrm{C}$, immunoelectrophoresis for properdin, $\beta_{1} \mathrm{C}$, and $\mathrm{C} 3 \mathrm{PA}$ was performed as described above.

\section{RESULTS}

Properdin. A statistically significant decrease in the serum level of properdin was noted in patients with CMPGN and AGN whose serum level of $\beta_{1} \mathrm{~A}$ was decreased more than 2 SD below the mean of normal values (165 \pm 82 ) (Table I and Appendix). The most striking decrease in serum levels of properdin was seen in patients with AGN (60 \pm 24$)$, and CMPGN (72 \pm 15$)$; a nonsignificant decrease was observed in sera from patients with SLE $(90 \pm 25)$. The level in patients with other renal diseases (124 \pm 43 ) was not significantly different from control values. Comparison of the serum properdin levels in the normal to the low $\beta_{1}$ A subgroups

\section{TABLE II}

Correlation Coefficients of Serum Levels of $\beta_{1} A$ i's. Properdin and $\beta_{1} A$ vs. C3PA in Patients with CMPGN, AGN, SLE,

Other Renal Disease, and Normal Subjects. If More than One Serum was Available from Each Patient, then a Single Serum Was randomly Selected.*

\begin{tabular}{|c|c|c|c|c|}
\hline \multirow[b]{2}{*}{ Disease } & \multicolumn{2}{|c|}{$\beta_{1}$ A vs. properdin } & \multicolumn{2}{|c|}{$\beta_{1} A$ vs. C3PA } \\
\hline & $r_{+}^{+}$ & $P$ & $r$ & $P$ \\
\hline CMPGN & 0.626 & $P<0.005$ & 0.131 & $0.1<P$ \\
\hline SLE & 0.229 & $0.1<P$ & 0.567 & $P<0.05$ \\
\hline$A G N$ & 0.844 & $P<0.001$ & 0.014 & $0.1<P$ \\
\hline Other renal disease: & 0.647 & $P<0.005$ & 0.595 & $P<0.02$ \\
\hline Normal & 0.027 & $0.1<P$ & 0.510 & $P<0.005$ \\
\hline
\end{tabular}

* Regression analysis by method of least squares.

$\ddagger r$ is correlation coefficient of the regression line.

of each disease category demonstrated a significant difference in the properdin level in CMPGN and AGN but no difference for SLE.

A positive correlation between serum levels of $\beta_{1} \mathrm{~A}$ and properdin was seen in patients with AGN $(P<0.001)$, CMPGN $(P<0.005)$, and other renal diseases $(P<$ 0.005 ) but not in patients with SLE or normal individuals when regression analysis was calculated from values for $\beta_{1} \mathrm{~A}$ vs. properdin (Table II, Fig. 1).

Six patients with CMPGN were studied by sequential properdin assays over 3-12 mo (Fig. 2). Although there was variability, serum properdin levels generally fluc-

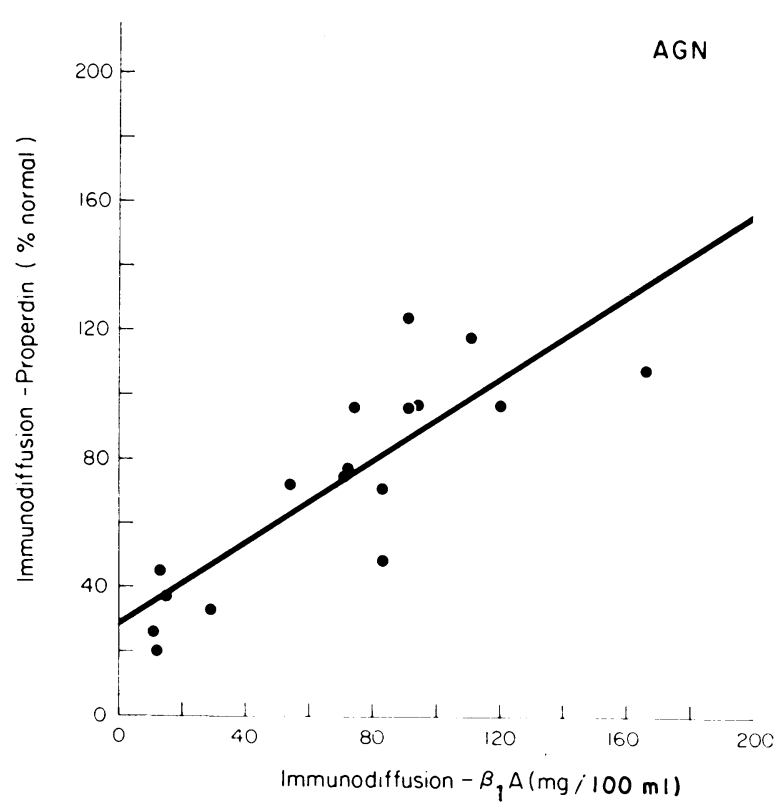

Figure 1 Regression line of $\beta_{1} \mathrm{~A}$ vs. properdin in patients with AGN. Single serum specimens from 17 patients were randomly selected and examined. The correlation coefficient is 0.844 . Method of least squares.

Properdin and C3PA in Glomerulonephritis 


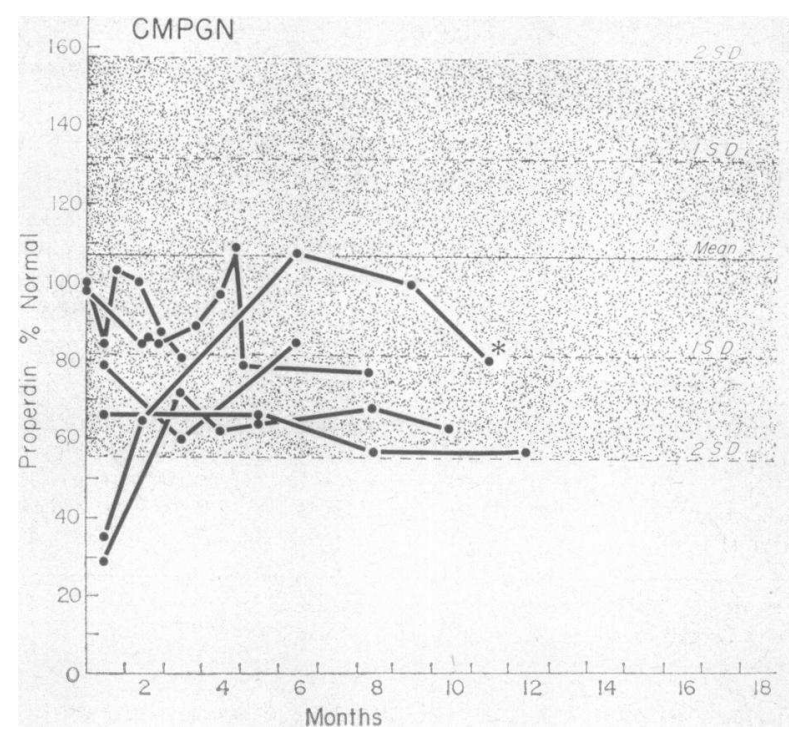

FIGURE 2 Serum properdin levels in six patients with CMPGN. Sera were collected over 3-12 mo. Properdin levels varied in the 2 SD below the mean. One patient $\left(^{*}\right)$ received immunosuppressive therapy. Shaded area represents the normal range of properdin $\pm 2 \mathrm{SD}$.

tuated within 1-2 SD below the mean. In two instances initially low values increased significantly. By contrast, in two patients with nonepidemic AGN, from whom re-
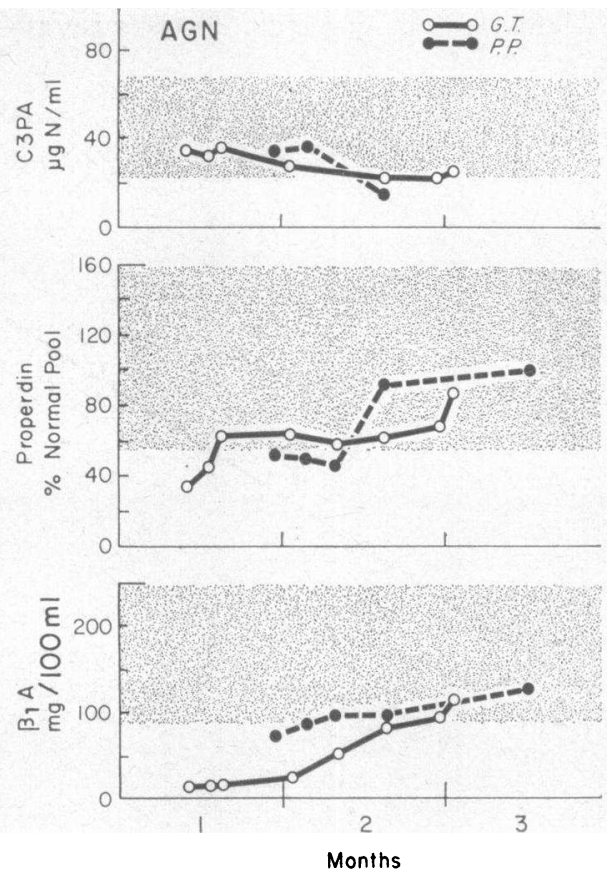

Figure $3 \beta_{1} \mathrm{~A}$, properdin, and C3PA serum levels in two patients with nonepidemic AGN. Shaded area represents normal range $\pm 2 \mathrm{SD}$. Properdin and $\beta_{1} \mathrm{~A}$ increased to normal within 2 mo while C3PA showed a slight decrease. peated serum specimens were otbained over a period of 3 mo, serum properdin levels increased rapidly toward the mean during the first 2 mo of illness (Fig. 3). In epidemic AGN, the serum properdin level was less than $2 \mathrm{SD}$ below the mean in $9 / 12$ patients in whom the date of onset of symptoms was known; all but one of these nine sera were taken within the first 15 days after onset of symptoms. The variation of serum properdin levels in one patient (E. B.) with SLE during azathioprine and prednisone therapy is shown in Fig. 4. A similar pattern of gradual increase with clinical improvement of the disease was noted in three other patients (L. P., M. T., G. O.) with SLE (Table III). One of these patients (L. P.) showed a decline of serum properdin from previously higher levels with clinical exacerbation of the disease (not shown).

The only group of patients receiving immunosuppressive therapy in this study were those with SLE. Six were evaluated before institution of immunosuppressive therapy, one was studied while on low dose, alternate day prednisone, and one had been on prednisone daily for 1 mo without response. The mean properdin level
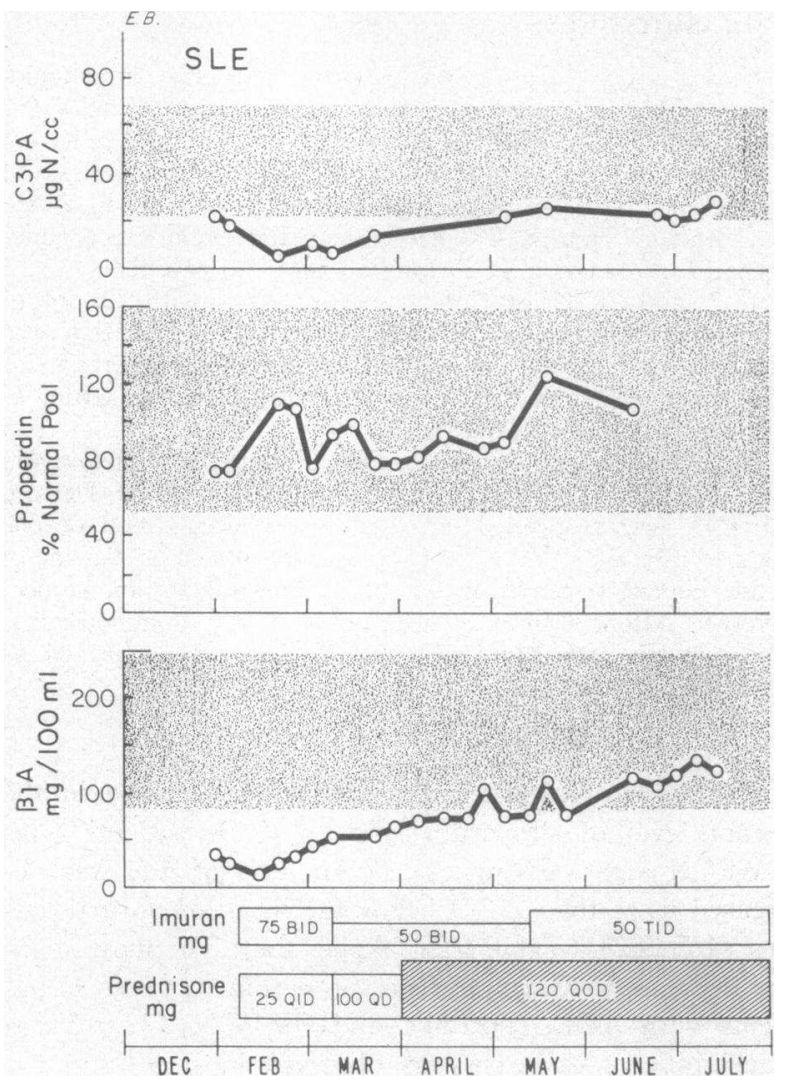

Figure 4 Serum $\beta_{1} A$, properdin, and C3PA levels in one patient (E. B.) with SLE. Shaded area includes normal range $\pm 2 \mathrm{SD}$. C3PA and $\beta_{1} \mathrm{~A}$ levels increased concomitantly on therapy. 
TABLE III

Relationship in Patients with SLE of Immunoelectrophoretic Migration of Properdin to Serum Levels of $\beta_{1} A$, Properdin, and C3P $A^{*}$

\begin{tabular}{|c|c|c|c|c|c|c|}
\hline Patient & Therapy $\ddagger$ & $\begin{array}{l}\text { Duration } \\
\text { of therapy }\end{array}$ & $\beta_{1} \mathrm{~A}$ & Properdin & C3PA & IEP\& \\
\hline & & mo & $\mathrm{mg} / 100 \mathrm{ml}$ & \% normal & $\mu g \mathrm{~N} / \mathrm{ml}$ & \\
\hline \multirow[t]{4}{*}{ 1. E. B. } & $\mathrm{P}, \mathrm{A}$ & 1 & 53 & 94 & 8 & $\mathrm{C}$ \\
\hline & & 2 & 66 & 77 & 20 & C \\
\hline & & 4 & 77 & 111 & 21 & $\mathrm{~N}$ \\
\hline & & 6 & 135 & 135 & 24 & $\mathrm{~N}$ \\
\hline \multirow[t]{4}{*}{ 2. L. P. } & $\mathrm{P}$ & 0 & 25 & 43 & 30 & $\mathrm{C}$ \\
\hline & & 6 & 65 & 68 & 29 & $\mathrm{~N}$ \\
\hline & & 6.5 & 67 & 64 & 16 & $\mathrm{C}$ \\
\hline & $\mathrm{P}, \mathrm{A}$ & 8 & 120 & 106 & 23 & $\mathrm{C}$ \\
\hline \multirow[t]{3}{*}{ 3. G. O. } & $\mathrm{P}$ & 0 & 31 & 112 & 28 & $\mathrm{C}$ \\
\hline & & 0.25 & 101 & 133 & 24 & $\mathrm{C}$ \\
\hline & & 2.5 & 197 & 160 & 50 & $\mathrm{C}$ \\
\hline \multirow[t]{3}{*}{ 4. M. T. } & $\mathrm{P}$ & 5 & 59 & 72 & 17 & $\mathrm{C}$ \\
\hline & $\mathrm{P}, \mathrm{A}$ & 6 & 94 & 72 & 17 & $\mathrm{C}$ \\
\hline & & 7.5 & 126 & 130 & 36 & $\mathrm{C}$ \\
\hline \multirow[t]{2}{*}{ 5. K. G. } & & 0 & 31 & 55 & 35 & $\begin{array}{r}\text { Arc not } \\
\text { visible }\end{array}$ \\
\hline & $\mathrm{P}, \mathrm{A}$ & 2 & 126 & 89 & & $\mathrm{~N}$ \\
\hline
\end{tabular}

* Normal values $\beta_{1} \mathrm{~A} 165 \pm 41 \mathrm{mg}$ per $100 \mathrm{ml}$, properdin $107 \pm 17 \%$, C3PA $46 \pm 12 \mu \mathrm{g} \mathrm{N}$ per ml. $\ddagger \mathrm{P}$, prednisone; $\mathrm{A}$, azathioprine

§ IEP, immunoelectrophoretic migration of properdin; $N$, normal_migration; $\mathrm{C}$, increased cathodal migration.

$(74 \pm 25)$ of the untreated SLE patients showed a significant difference from the normal controls but not from the remaining SLE patients in the low $\beta_{1} \mathrm{~A}$ and normal $\beta_{1} \mathrm{~A}$ groups.

$C 3 P A$. A statistically significant reduction in serum C3PA was found in patients with low $\beta_{1} A$ in CMPGN $(33 \pm 7)$ and SLE (27 \pm 9$)$. Sera with normal $\beta_{1} A$ levels

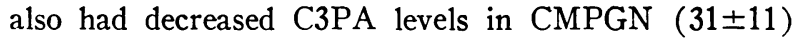
and SLE (33 \pm 9$)$. The decreased C3PA levels in CMPGN did not correlate with the level of renal function. In SLE serum C3PA levels 2 SD below the mean were found in six patients. Five of the six had severe lupus nephritis and abnormalities of renal function. A significant decrease in serum C3PA was seen in AGN sera with low $\beta_{1} A(36 \pm 10)$ but not in sera with normal $\beta_{1} A$. No differences were noted when levels in other renal diseases were compared with normal values.

Statistical analysis of the regression lines of $\beta_{1} \mathrm{~A}$ vs. C3PA with one serum from each patient is shown in Table II. The $r$ value derived from analyses of C3PA and $\beta_{1} A$ levels was significantly different from zero in SLE, other renal diseases, and in the normal population but not for CMPGN and AGN.
A scattergram of C3PA levels in 40 sera from 21 patients with SLE is shown in Fig. 5 and illustrates the positive relationship between serum levels of $\beta_{1} \mathrm{~A}$ and

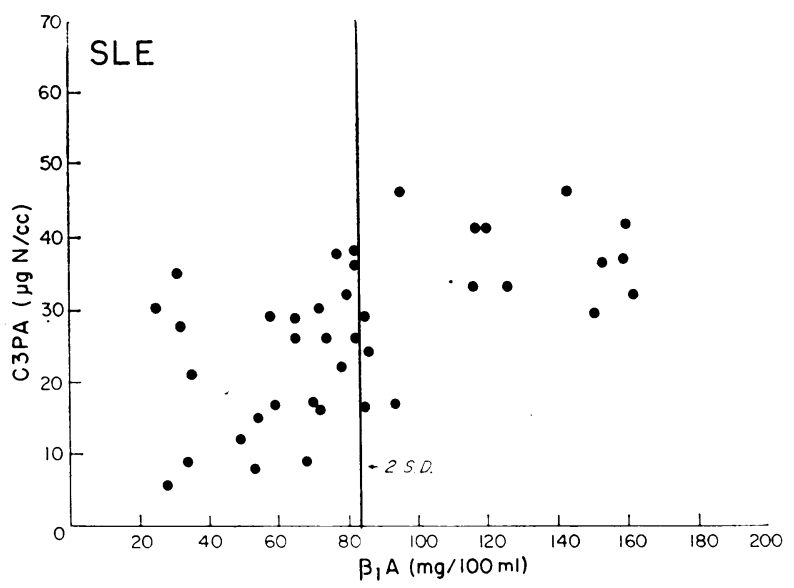

FIgURE 5 Scattergram of $\beta_{1} A$ vs. C3PA of 40 sera from 21 patients with SLE. Vertical line indicates $\beta_{1} \mathrm{~A}$ level 2 $\mathrm{SD}$ below the mean. A positive correlation was shown to be present by regression analysis of a single serum from each patient.

Properdin and C3PA in Glomerulonephritis 
C3PA. Longitudinal studies of a patient with SLE over a period of 7 mo shows the effect of immunosuppressive therapy on C3PA levels (Fig. 3). In this patient, values $2 \mathrm{SD}$ below the mean of serum C3PA rose to normal as $\beta_{1} A$ levels increased. Three other patients (G. O., M. T., L. P.) followed 3-9 mo with SLE showed increasing levels of C3PA with clinical improvement (Table III).

The mean serum C3PA level in the eight patients with SLE evaluated before immunosuppressive therapy or
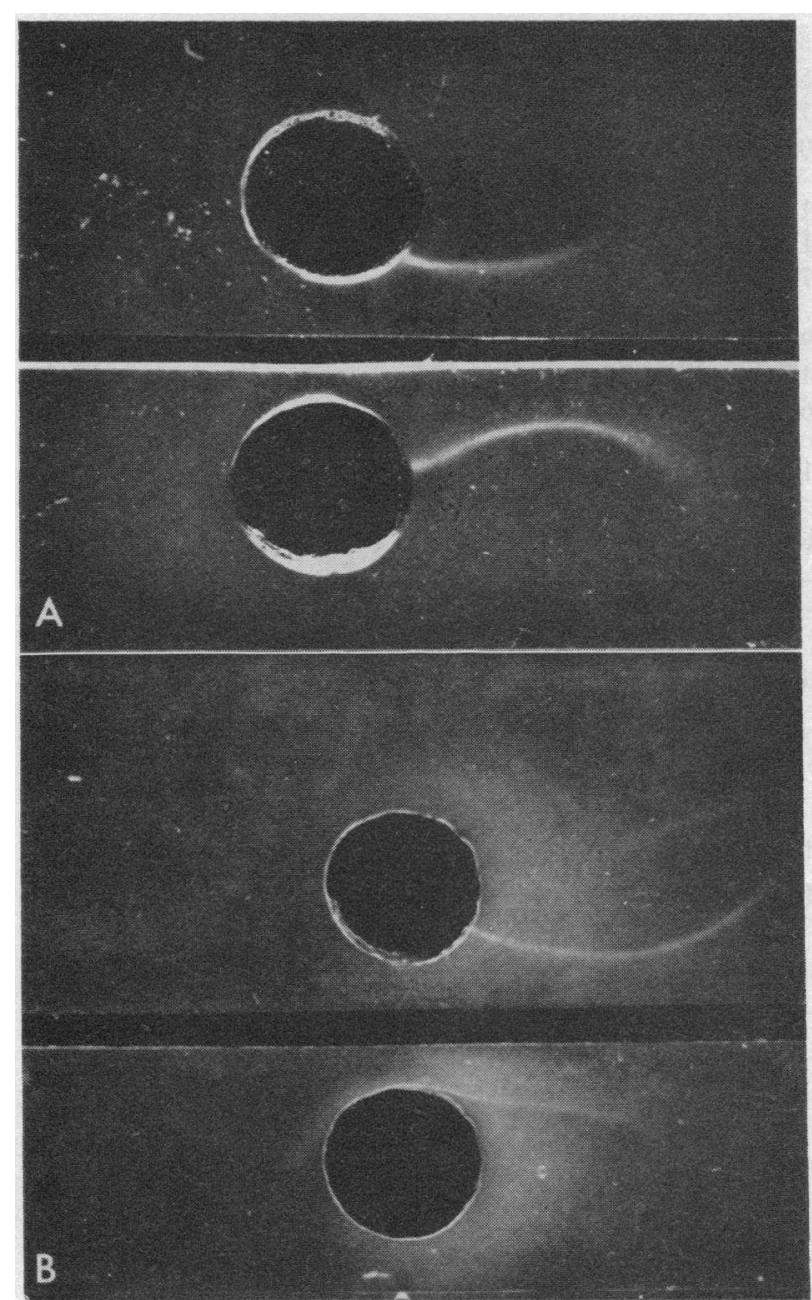

Figure 6 Immunoelectrophoretic pattern of serum properdin. (A) A normal serum is in the upper well; patient's serum with SLE (E. B.) is in the lower well. RAHP was placed in the trough. Cathode on the right. Compared to the control serum, the precipitin arc arises more posteriorly in the well, and the point of greatest curvature of the precipitin arc has shifted toward the cathode (Pc). (B) A normal control serum is on the lower well; serum from a patient with active SLE is in the upper well. RAHP is placed in the trough. Cathode on the right. SLE serum precipitin arc is shifted cathodally when compared to the normal control serum. while on alternate day predisone was $30 \pm 5 \mu \mathrm{g} \mathrm{N}$ per $\mathrm{ml}$ and did not differ significantly from levels of the low or normal $\beta_{1} A$ subgroups. Comparison of the low $\beta_{1} A$ group to the normal $\beta_{1} \mathrm{~A}$ group within each disease category showed no significant difference in serum C3PA levels for CMPGN, SLE, and AGN. Sequential serum C3PA levels examined over 3 mo decreased in one patient with AGN (P. P.) shown in Fig. 3, but remained in the low range in the second (G. T.). In eight patients with CMPGN who had two or more sera available, serum C3PA levels were lower than the mean but within the range of normal.

Immunoelectrophoresis. 19 normal patients (without renal disease) showed a properdin precipitin arc in the $\beta$-globulin region on immunoelectrophoresis (Fig. 6).

Four of five patients with SLE evaluated sequentially had sera demonstrating increased cathodal migration of properdin on immunoelectrophoresis (designated Pc) when compared to normal sera (Table II and Fig. 6). Patients 1 and 2 had abnormal migration of properdin during periods of activity but normal migration during remission. Sera from patient 5 and one other patient with SLE had properdin levels 2 SD below the mean ( 55 and $47 \%$ of normal); properdin could not be detected in either sera by immunoelectrophoresis. A similar evaluation of sera from four other patients with treated SLE revealed normal properdin migration in two and indeterminate results in two. Sera from 5 of 15 patients with CMPGN also showed increased cathodal migration of properdin. This could not clearly be correlated with the activity of the renal disease. A similar analysis of 10 sera from four patients with sporadic AGN failed to detect any abnomalities. Immunoelectrophoresis of sera from 10 patients (12 sera) with other forms of renal disease have not shown any with cathodal migration of properdin.

After incubation of normal human serum with 1,2 , and $20 \mathrm{U}$ of $\mathrm{CoF}$ per $\mathrm{ml}$ of sera, increased cathodal migration of properdin was observed on immunoelectrophoresis at all concentrations of $\mathrm{CoF}$ (Fig. 7). Similar changes could be seen after incubation of serum with endotoxin in a concentration of $3.6,12$, and $90 \mu \mathrm{g}$ per $\mathrm{ml}$ of serum. Double diffusion in agarose of normal sera and sera with abnormal properdin migration against RAHP did not show spurring. No antigenic loss could be demonstrated after incubation with $\mathrm{CoF}$ or endotoxin. Immunodiffusion assay of properdin showed no change in concentration after incubation with $\mathrm{CoF}$ or endotoxin. Agarose, Ionagar, and barbital buffer ( $\mathrm{pH}$ 8.6) were found to be less satisfactory for the demonstration of properdin by immunoelectrophoresis. Immunoelectrophoresis for C3PA in aliquots of the above sera showed a new $\gamma$-migrating arc in addition to the $\beta$-arc noted in control sera. Immunoelectrophoresis for $\beta_{1} \mathrm{C} / \beta_{1} \mathrm{~A}$ dem- 
onstrated the appearance of a new arc more anodal to the $\beta$-migrating arc for $\beta_{1} \mathrm{C}$.

\section{DISCUSSION}

The significance of an alternate complement pathway in human disease, particularly immune-related glomerulonephritis, is unknown. These studies have attempted to define the role of two components in this pathway, properdin and C3PA, in patients who are known to have alterations in the serum level of complement or its components and immunopathologic evidence of complementmediated glomerular injury. It is recognized that the precise relationship between properdin and the $\mathrm{C} 3$ proactivator system has not been defined, and that serum levels of the components of the complement pathways are static values which reflect the net effect of several forces.

A decrease in serum hemolytic complement has been observed in a number of different forms of glomerulonephritis including AGN, CMPGN, SLE, and certain instances of infection and nephritis (21-25). Examination of the serum complement components has shown that CMPGN is characterized by relatively normal early components ( $\mathrm{C} 1, \mathrm{C} 4, \mathrm{C} 2)$, and depression of terminal components (C3-C9), whereas in patients with active SLE all components are decreased. In AGN all components with the frequent exception of $\mathrm{C} 1 \mathrm{q}$ are decreased early but only C3 is decreased later in the disease. Gewurz et al. noted the similarity of the complement component profile produced by lipopolysaccharides and polysaccharides to that noted in CMPGN and AGN (8). Participation of the alternate pathway in diffuse glomerular disease associated with hypocomplementemia is suggested by the results of the present study: depression of serum levels of properdin and C3PA, a correlation between the levels of $\beta_{1} C$ with properdin and/or C3PA in some diseases but not others, and changes in the electrophoretic migration of serum properdin in vivo. The patients with glomerulonephritis have been evaluated on the basis of the serum level of $\beta_{1} A$ since both properdin and C3PA participate in the activation of $\mathrm{C} 3$. This separation is an arbitrary one, and it is recognized that certain values in the normal $\beta_{1} \mathrm{~A}$ groups are still different from normal.

Patients with AGN had the lowest levels of serum properdin and showed the closest correlation with serum $\beta_{1} \mathrm{~A}$. With two exceptions, all properdin values which were less than $2 \mathrm{SD}$ below the mean were detected in sera drawn within 2 wk of the onset of clinical illness. In sequential studies in two patients, properdin and $\beta_{1} A$ levels showed a concomitant return to normal. Significant C3PA depression occurred in AGN, but the serum level was less depressed than in CMPGN or SLE. Patients with CMPGN resembled AGN in the significant depres-

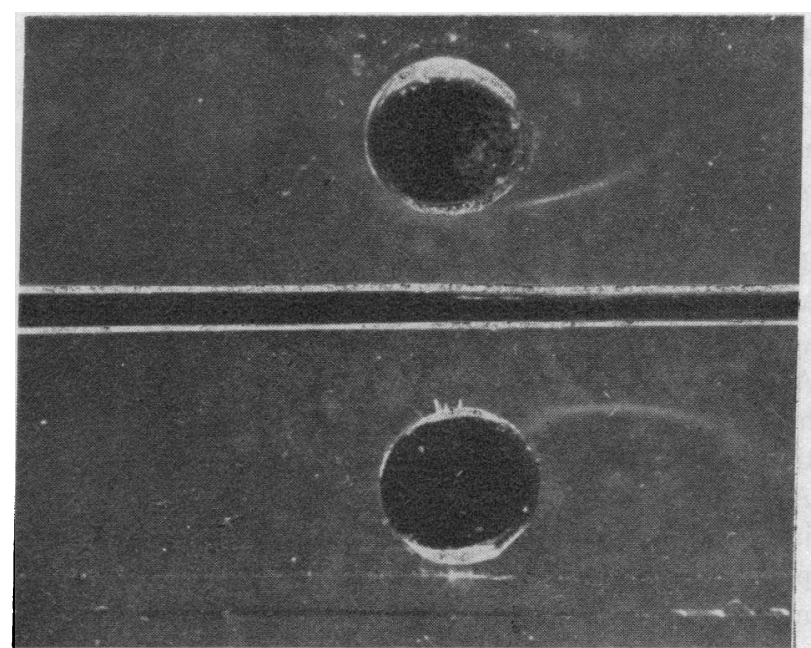

FIGURE 7 Immunoelectrophoretic pattern of serum properdin incubated with $\mathrm{CoF}$. Normal serum control is in upper well. $0.1 \mathrm{ml}$ of same serum incubated with $2 \mathrm{U}$ of CoF (20 U per $\mathrm{ml}$ ) in bottom well. Cathode on the right. The precipitin arc in the serum incubated with $\mathrm{CoF}$ shows abnormal cathodal migration $(\mathrm{Pc})$ similar to that noted in the SLE sera of Fig. 6.

sion in levels of properdin and C3PA and the positive correlation between $\beta_{1} A$ and properdin, but not between $\beta_{1} A$ and C3PA. Unlike AGN, five patients with CMPGN had one or more sera with abnormal migration of properdin on immunoelectrophoresis.

C3PA was most significantly decreased in SLE and increased to normal as the serum $\beta_{1} \mathrm{~A}$ level returned to normal in response to immunosuppressive therapy. Four patients studied during periods of hypocomplementemia showed abnormal migration of properdin on immunoelectrophoresis, and in two patients this has become normal with remission of the disease. Serum properdin was not significantly depressed in sera from SLE patients with low $\beta_{1} \mathrm{~A}$, but a significant decrease was present in SLE patients who were not yet on immunosuppressive therapy or who were early in the treatment course.

It is of interest that a positive correlation was shown between $\beta_{1} \mathrm{~A}$ and $\mathrm{C} 3 \mathrm{PA}$ for SLE and normal sera. Normal sera did not show a positive correlation of $\beta_{1} \mathrm{~A}$ vs. properdin. The reason for this difference between C3PA and properdin in normal sera is unknown. Similarly, the significance of the positive correlation between $\beta_{1} A$ and both properdin and C3PA in other renal diseases is not known.

Cathodal migration of properdin $(\mathrm{Pc})$ was never detected in sera from normal patients or patients with renal disease other than SLE or CMPGN. However, cathodal migration has been demonstrated in aging serum (18) or after incubation with $\mathrm{CoF}$ and endotoxin. 
In SLE and CMPGN, Pc may represent a different form of properdin which has resulted from in vivo activation of the alternate pathway. Since certain antigens may have been lost from the molecule during isolation procedures or may be present in such small concentrations as to be undetectable by immunodiffusion, it is possible that the change in electrophoretic migration occurs without the appearance or disappearance of different antigens recognized by the antiproperdin serum used. A change of some type in the properdin molecule must have occurred to cause the increased cathodal migration, but the nature of this change is unknown. In early AGN, serum properdin was too low to be detected on immunoelectrophoresis but when the concentration of properdin subsequently increased, no abnormality was noted. Evidence against the possibility that changes in serum concentration of properdin resulted in immunoelectrophoretic change include: normal serum properdin levels in patients with abnormal migration (Table III, cases 1-4), absence of cathodal migration with dilution of normal serum, and no change in properdin concentration by immunodiffusion assay after incubation with $\mathrm{CoF}$ or endotoxin.

The question of the biologic importance of the alternate pathway of complement activation is unknown. Properdin has been found deposited on glomeruli in CMPGN, AGN, some cases of SLE and in other renal disease (9). Utilizing the zymosan assay, serum levels of properdin have been noted to be decreased in some forms of renal disease (8), but the zymosan assay shows a $26 \%$ incidence of low titers in normal subjects (7), and it is probable that this assay is influenced by other proteins besides properdin. The C3PA system has been found to be necessary in the mediation of paroxysmal hemoglobinuria (26), but we have not detected glomerular deposition of C3PA in human glomerulonephritis. Alper has shown that glycine-rich $\beta$-glycoprotein functions as Factor B in the properdin system (13), and he has described one patient with a congenital deficiency of glycine-rich $\beta$-glycoprotein who has decreased C3 and has had a lifelong history of serious infections (27). This suggests that the alternate pathway may be involved in defense against infection.

The mechanism of activation of the alternate pathway in human glomerulonephritis is unknown. A C3 nephritic factor ( $\mathrm{C} 3 \mathrm{Nef})$ has been described in patients with CMPGN which activated $\mathrm{C} 3$ to $\beta_{1} \mathrm{~A}$ and $\alpha_{2} \mathrm{D}$ in the presence of cofactor and magnesium (28). C3 nephritic factor is not C3PA but apparently requires C3PA for $\mathrm{C} 3$ activation (29). Müller-Eberhard and Götze (12) have shown that once $\mathrm{C} 3$ is activated to $\mathrm{C} 3 \mathrm{~b}$ and $\mathrm{C} 3 \mathrm{a}$, the C3PA system is activated and becomes autocatalytic. In this situation, activation of the classical complement pathway would be expected to recruit the alternate pathway, and this is consistent with the depressed levels of C3PA in SLE noted in this study. However, in diseases such as CMPGN in which only the terminal complement components are decreased, a separate mechanism to first activate C3 must exist, and, as suggested by MüllerEberhard and Götze, the properdin system could act at this point. It is of significance that a circulating abnormal form of properdin has been detected in CMPGN and SLE which can be produced in vitro by known activating factors of the alternate pathway.

TABLE IV

Statistical Evaluation of Mean Serum Levels of $\beta_{1} A$, Properdin, and C3PA in Patients with CMPGN, SLE, AGN, and Other Renal Disease. Low and Normal $\beta_{1} A$ groups within Each Disease Category Compared to Normal Controls by Method of Dunnett (30)

\begin{tabular}{|c|c|c|c|c|c|c|c|c|c|c|}
\hline \multirow[b]{3}{*}{ Disease } & \multirow[b]{3}{*}{$\beta_{1} \mathrm{~A}$ groups } & \multicolumn{3}{|c|}{$\beta_{1} \mathrm{~A}$} & \multicolumn{3}{|c|}{ Properdin } & \multicolumn{3}{|c|}{ C3PA } \\
\hline & & \multirow[b]{2}{*}{$\left(\bar{x}_{\iota}-\bar{x}_{c}\right)^{*}$} & \multicolumn{2}{|c|}{$\begin{array}{l}\text { Simultaneous } \\
\text { 95\% confidence } \\
\text { intervals }\end{array}$} & \multirow[b]{2}{*}{$\left(\bar{x}_{t}-\bar{x}_{c}\right)$} & \multicolumn{2}{|c|}{$\begin{array}{l}\text { Simultaneous } \\
95 \% \text { confidence } \\
\text { intervals }\end{array}$} & \multirow[b]{2}{*}{$\left(\bar{x}_{t}-\bar{x}_{c}\right)$} & \multicolumn{2}{|c|}{$\begin{array}{l}\text { Simultaneous } \\
95 \% \text { confidence } \\
\text { intervals }\end{array}$} \\
\hline & & & $\begin{array}{l}\text { Lower } \\
\text { limit }\end{array}$ & $\begin{array}{l}\text { Upper } \\
\text { limit }\end{array}$ & & $\begin{array}{l}\text { Lower } \\
\text { limit }\end{array}$ & $\begin{array}{l}\text { Upper } \\
\text { limit }\end{array}$ & & $\begin{array}{l}\text { Lower } \\
\text { limit }\end{array}$ & $\begin{array}{l}\text { Upper } \\
\text { limit }\end{array}$ \\
\hline CMPGN & Low $\beta_{1} \mathrm{~A}$ & -123 & -147.0 & -99 & -35 & -55 & -15 & -13 & -22 & -4 \\
\hline SLE & “ $\quad$. & -144 & -125 & -75 & -17 & -38 & 4 & -19 & -28 & -10 \\
\hline AGN & . $\quad$ “ & -121 & -147 & -95 & -47 & -69 & -2.5 & -10 & -20 & -0.55 \\
\hline CMPGN & Normal $\beta_{1} \mathrm{~A}$ & -50 & -79 & -21 & -15 & -39 & 9 & -15 & -27 & -3 \\
\hline SLE & " $\quad$ " & -59 & -89 & -29 & -12 & -37 & 13 & -13 & -24 & -2 \\
\hline AGN & “. & -52 & -82 & -22 & -12 & -37 & 13 & 0 & -11 & 11 \\
\hline $\begin{array}{l}\text { Other renal } \\
\text { diseases }\end{array}$ & “ & -14 & -38 & 10 & 17 & -3 & 37 & -6 & -15 & 3 \\
\hline SLE-untreated & Low $\beta_{1} \mathrm{~A}$ & -112 & -144 & -79 & -32 & -60 & -5 & -17 & -28 & -6 \\
\hline SLE-treated & ". '. & -90 & -122 & -58 & -9 & -36 & 18 & -19 & -31 & -7 \\
\hline
\end{tabular}

$*\left(\bar{x}_{t}-\bar{x}_{c}\right)$ is the difference of the mean serum level of the disease group $\left(\bar{x}_{t}\right)$ from the mean of the normal controls $\left(\bar{x}_{c}\right)$. 


\section{APPENDIX}

All mean serum $\beta_{1}$ A levels were significantly decreased at $5 \%$ simultaneous significance level when compared to normal in all disease groups, except other renal diseases. Although within the normal range, mean $\beta_{1} \mathrm{~A}$ levels were still significantly different from normal in normal $\beta_{1} \mathrm{~A}$ subgroups of each disease category (Table IV).

Compared to normal controls mean serum properdin levels were significantly decreased in the low $\beta_{1} \mathrm{~A}$ subgroups of patients with CMPGN and AGN; SLE patients with low $\beta_{1} \mathrm{~A}$ were not significantly different, but untreated patients with SLE and low $\beta_{1} \mathrm{~A}$ were significantly decreased.

Mean serum C3PA levels were significantly decreased in all diseases except the normal $\beta_{1} \mathrm{~A}$ subgroups of patients with AGN and other renal diseases.

Addendum. Since submission of this manuscript, other workers have reported data of serum levels of Factor $B$ (glycine-rich $\beta$-glycoprotein, C3PA) in human glomerulonephritis. (Hunsicker, L. G., S. Ruddy, C. B. Carpenter, P. H. Schur, J. P. Merrill, H. J. Müller-Eberhard, and K. F. Austin. 1972. Metabolism of third complement component (C3) in nephritis. Involvement of the classic and alternate (properdin) pathways for complement activation. N. Engl. J. Med. 287: 835.)

Decreased serum levels of Factor B were found in 8 of 12 patients with SLE and nephritis and in 6 of 12 patients with CMPGN.

\section{ACKNOWLEDGMENTS}

The authors gratefully acknowledge the gift of C3PA antiserum from $H$. J. Müller-Eberhard. C. West has kindly performed $\beta_{1} \mathrm{~A}$ assays on several reference sera. We express our sincere appreciation for the expert technical assistance of Kay Townsend and Fern Knudson. The statistical studies were performed under the guidance of Dr. James Boen to whom we express our thanks.

This work was supported by grants from the National Institutes of Health (AM 12375, AI 10704, HE 06314), the American Heart Association, and the Kidney Foundation of the Upper Midwest.

\section{REFERENCES}

1. Fish, A. J., A. F. Michael, and R. A. Good. 1971. Pathogenesis of glomerulonephritis. In Diseases of the Kidney. M. B. Strauss and L. G. Welt, editors. Little, Brown and Company, Boston, Mass. 2nd edition. 373.

2. Pillemer, L., L. Blum, I. H. Lepow, O. A. Ross, E. W. Todd, and A. C. Wardlaw. 1954. The properdin system and immunity. I. Demonstration and isolation of a new serum protein. Science (Wash. D. C.). 120: 279.

3. Sandberg, A. L., A. G. Osler, H. S. Shin, and B. Oliveira. 1970. The biologic activities of guinea pig antibodies. II. Modes of complement interaction with $\gamma 1$ and $\gamma 2$ immunoglobulins. J. Immunol. 104: 329.

4. Götze, O., and H. J. Müller-Eberhard. 1971. The C3activator system: An alternate pathway of complement activation. J. Exp. Med. 134: 905.

5. Pensky, J., T. Wurz, L. Pillemer, and I. H. Lepow. 1959. The properdin system and immunity. XII. Assay properties and partial purification of a hydrazine-sensitive serum factor (Factor A) in the properdin system. Z. Immunitaetforsch. 118: 329.

6. Blum, L., L. Pillemer, and I. H. Lepow. 1959. The properdin system and immunity. XIII. Assay and properties of a heat-labile serum factor (Factor B) in the properdin system. Z. Immunitaetforsch. 118: 349.

7. Soulier, J. P., and D. Menaché. 1958. Variations pathologiques du complement et de la properdine chez l'homme. Acta Haematol. (Basel). 20: 260.

8. Gewurz, H., R. J. Pickering, G. Naff, R. Snyderman, S. E. Mergenhagen, and R. A. Good. 1969. Decreased properdin activity in acute glomerulonephritis. Int. Arch. Allergy Appl. Immunol. 36: 592.

9. Westberg, N. G., G. B. Naff, J. T. Boyer, and A. F. Michael. 1971. Glomerular deposition of properdin in acute and chronic glomerulonephritis with hypocomplementemia. J. Clin. Invest. 50: 642.

10. Oliveira, B., A. G. Osler, R. P. Siraganian, and A. L. Sandberg. 1970. The biologic activities of guinea pig antibodies. I. Separation of $\gamma 1$ and $\gamma 2$ immunoglobulins and their participation in allergic reactions of the immediate type. J. Immunol. $104: 320$.

11. Sandberg, A. L., O. Götze, H. J. Müller-Eberhard, and A. G. Osler. 1971. Complement utilization by guinea pig $\gamma 1$ and $\gamma 2$ immunoglobulins through the C3 activator system. J. Immunol. 107: 920.

12. Müller-Eberhard, H. J., and O. Götze. 1972. C3 proactivator convertase and its mode of action. J. Exp. Med. 135 : 1003.

13. Alper, C. A., I. Goodkofsky, and I. H. Lepow. 1972. Studies of glycine-rich $\beta$-glycoprotein (GBG), properdin factor $\mathrm{B}$ and $\mathrm{C} 3$ proactivator (C3PA). Fed. Proc. 31: 787. (Abstr.)

14. Fish, A. J., R. C. Herdman, A. F. Michael, R. J. Pickering, and R. A. Good. 1970. Epidemic acute glomerulonephritis associated with type 49 streptococcal pyoderma. II. Correlation study of light, immunofluorescent and electron microscopic findings. $A m$. J. Med. 48: 28.

15. Mancini, G., A. O. Carbonara, and J. F. Heremans. 1965. Immunochemical quantitation of antigens by single radial immunodiffusion. Immunochemistry. 2: 235.

16. Müller-Eberhard, H. J., U. Nilsson, and T. Aronsson. 1960. Isolation and characterization of two $\beta_{1}$-glycoproteins of human serum. J. Exp. Med. 111: 201.

17. Pensky, J., C. F. Hinz, Jr., E. W. Todd, R. J. Wedgewood. J. T. Boyer, and I. H. Lepow 1968. Properties of highly purified human properdin. J. Immunol. 100: 142.

18. McLean, R. H., and A. F. Michael. 1972. The immunoelectrophoretic pattern of properdin in fresh and aged human serum. Proc. Soc. Exp. Biol. Med. 141: 403.

19. Alper, C. A., T. Boenisch, and L. Watson. 1972. Genetic polymorphism in human glycine-rich $\beta$ glycoprotein. $J$. Exp. Med. $135: 68$.

20. Müller-Eberhard, H. J., and K. Fjellstrom. 1971. Isolation of the anticomplementary protein from cobra venom and its mode of action on C3. J. Immunol. 107: 1666.

21. Lange, K., F. Graig, J. Oberman, L. Slobody, G. Ogur, and F. LoCasto. 1951. Changes in serum complement during the course and treatment of glomerulonephritis. Arch. Intern. Med. 88: 433.

22. Gewurz, H., R. J. Pickering, S. E. Mergenhagen, and R. A. Good. 1968. The complement profile in acute

Properdin and C3PA in Glomerulonephritis 
glomerulonephritis, systemic lupus erythematosis and hypocomplementemic chronic glomerulonephritis. Int. Arch. Allergy Appl. Immunol. 34: 566.

23. Kohler, P. F., and R. Ten Bensel. 1969. Serial complement component alterations in acute glomerulonephritis and systemic lupus erythematosis. Clin. Exp. Immunol. 4: 191.

24. Lewis, E. J., C. B. Carpenter, and P. H. Schur. 1971. Serum complement component levels in human glomerulonephritis. Ann. Intern. Med. 75: 555.

25. Michael, A. F., N. G. Westberg, A. J. Fish, and R. L. Vernier. 1971. Studies on chronic membranoproliferative glomerulonephritis with hypocomplementemia. J. Exp. Med. $134: 208 \mathrm{~S}$.

26. Götze, O., and H. J. Müller-Eberhard. 1972. Paroxysmal nocturnal hemoglobulinuria. Hemolysis initiated by the C3 activator system. N. Engl. J. Med. 286: 180.
27. Alper, C. A., N. Abramson, R. B. Johnson, Jr., J. H. Jandl, and F. S. Rosen. 1970. Increased susceptibility to infection associated with abnormalities of complement-mediated functions and of the third component of complement (C3). N. Engl. J. Med. 282: 349.

28. Vallota, E. H., J. Forrestal, R. E. Spitzer, N. C. Davis, and C. D. West. 1970. Characteristics of a non-complement-dependent C3-reactive complex formed from factors in nephritic and normal serum. J. Exp. Med. $131: 1306$.

29. Ruley, E. J., J. Forrestal, C. Watson, N. C. David, and C. D. West. 1972. Relation of nephritic factor to alternate pathway in C3 breakdown. Fed. Proc. 31: 788.

30. Steele, R. G. D., and J. H. Torrie. 1960. Principles and Procedures of Statistics, McGraw-Hill Book Co., New York. 111. 